\title{
Spatial Decision Support Systems for Landscape Ecological Evaluations in the Southwest Florida Feasibility Study 1
}

\author{
Leonard Pearlstine, Donald L. DeAngelis, Frank J. Mazzotti, Tomma Barnes, Michael Duever and \\ Janet Starnes ${ }^{2}$
}

\section{Introduction}

The objective of the Southwest Florida Feasibility Study (SWFFS) is to develop a comprehensive and ecologically sound regional plan for water resources in southwestern Florida. Boundaries of the study are shown in fig. 1. The SWFFS study area covers about 4,300 square miles, and lies west of the Everglades and most Comprehensive Everglades Restoration Plan (CERP) activities. The study was recommended by CERP and the Comprehensive Review Study for inclusion in the Central and Southern Florida (C\&SF) Project because of: (1) water-supply and ecological issues with water releases from Lake Okeechobee to the Caloosahatchee River, and because (2) inland hydrologic alterations have substantial existing and potential effects on rich natural resources and biodiversity within the study area. This study will address the health of upland and aquatic ecosystems and will consider a variety of parameters including water flow, water quality, water supply, maintenance of existing flood protection, wildlife, biological diversity, and natural habitat. The SWFFS is being conducted by the U.S. Army Corps of Engineers and the South Florida Water Management District. The USGS, in cooperation with the University of Florida, is providing technical assistance for evaluation of hydrologic impacts to natural systems.

Landscape level decision-making is a process that involves multiple objectives, large data sets, and many unknowns and uncertainties. To support this process, evaluation tools are needed to make informed long-term regional resource decisions and recognize research needs. These tools can help authorities involved in ecological restoration by identifying decision variables, developing problem solving heuristics, and evaluating the consequences of alternative policy actions. Spatial decision support

1. This document is CIR 1479, one of a series of the Wildlife Ecology and Conservation Department, University of Florida Cooperative Extension Service, Institute of Food and Agricultural Sciences. Publication date: January, 2006. Visit the EDIS Web site at http://edis.ifas.ufl.edu. For a better understanding of figures and graphics, please print in a color printer.

2. Leonard Pearlstine and Frank J. Mazzotti, Principal Investigators, University of Florida, Ft. Lauderdale Research and Education Center, 3205 College Ave, Ft. Lauderdale, Florida, 33314, e-mails: pearlstn@ufl.edu, fjma@ufl.edu; Donald L. DeAngelis, Project Officer, U.S. Geological Survey, Florida Integrated Science Center, Water and Restoration Studies, University of Miami, P.O. Box 249118, Coral Gables, FL 33124, e-mail: ddeangelis@umiami.ir.miami.edu; Tomma Barnes, Michael Duever and Janet Starnes, Project Leaders, South Florida Water Management District, Lower West Coast Regional Service Center, 2301 McGregor Boulevard, Ft Myers, FL 33901, e-mails: tbarnes@ sfwmd.gov, mduever@sfwmd.gov, jstarne@sfwmd.gov.

The Institute of Food and Agricultural Sciences (IFAS) is an Equal Opportunity Institution authorized to provide research, educational information and other services only to individuals and institutions that function with non-discrimination with respect to race, creed, color, religion, age, disability, sex, sexual orientation, marital status, national origin, political opinions or affiliations. U.S. Department of Agriculture, Cooperative Extension Service, University of Florida, IFAS, Florida A. \& M. University Cooperative Extension Program, and Boards of County Commissioners Cooperating. Larry Arrington, Dean 


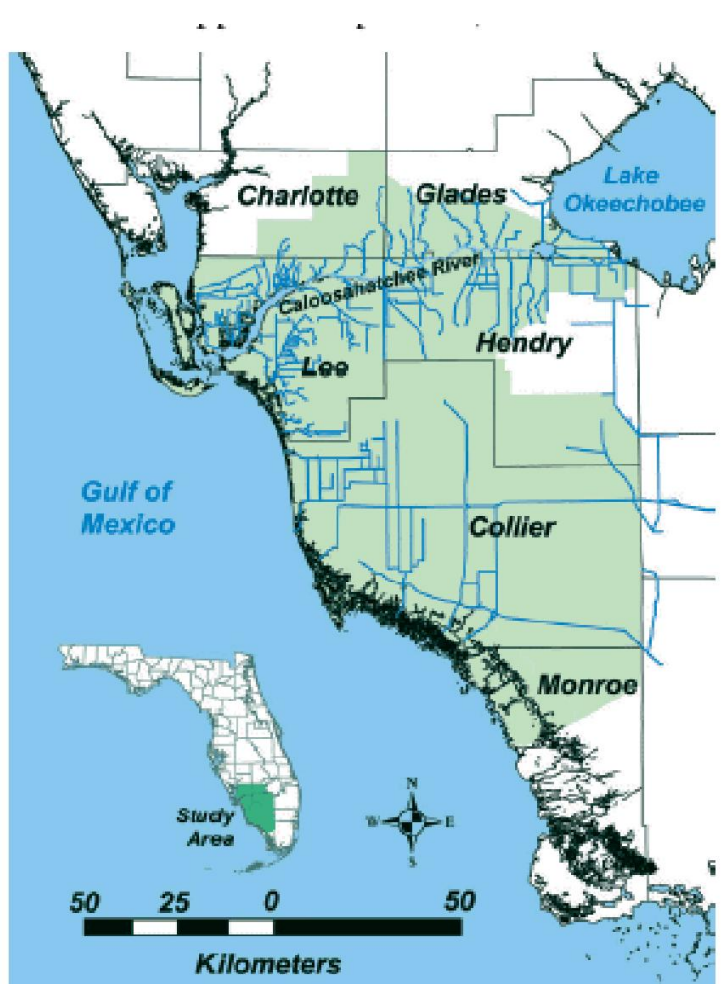

Figure 1. The Southwest Florida Feasibility Study area (shaded in green) showing major canals.

systems (SDSS) for natural resource management are computer-based tools that tightly integrate decision theory models with ecological models and Geographic Information System (GIS) analyses and mapping. The information provided by SDSS gives decision makers increased ability to follow outcomes of interacting variables, improves the reproducibility of decisions, and documents the reason why (with conflicting alternatives) a particular choice was made (Rauscher 1999).

The framework for decision support of landscape habitat evaluations has four components (Fig. 2). The first two components, primarily intended for use by the scientist, assist in assessing which criteria best define performance measures for ecological evaluation and which values those criteria will have with a particular scenario. The first component is an analysis of the proposed scenarios and their respective effects on the physical environment. These analyses are supported by inputs from models that simulate each scenario such as hydrologic models, urban growth models, and water-quality models. Tools provided in the second component evaluate effects on wildlife habitat and ecological communities caused by changes in the physical environment.
These tools evaluate habitat suitability and risk evaluations based on inputs from habitat models.

The third and fourth components are intended for use, respectively, by policy makers and the public. Decision models (the third component) rank and aid decisions among criteria and alternative scenarios. Evaluations of alternatives at this level may lead to modified or new scenarios, which would then be returned to scientists for evaluation using the support tools in the first two components. A graphical, public education version of the decision process (the final component) can increase public understanding of conservation actions, create a sense of involvement and "ownership" in decisions, and alert policy makers and resource managers to social judgments of alternative plans. A Web-based interface is one option for public and policy maker participation. The Internet has the advantages of removing geographic restrictions to participation, easy access to discussion materials, anonymous input and nonconfrontational feedback opportunities (Kingston and others, 2000).

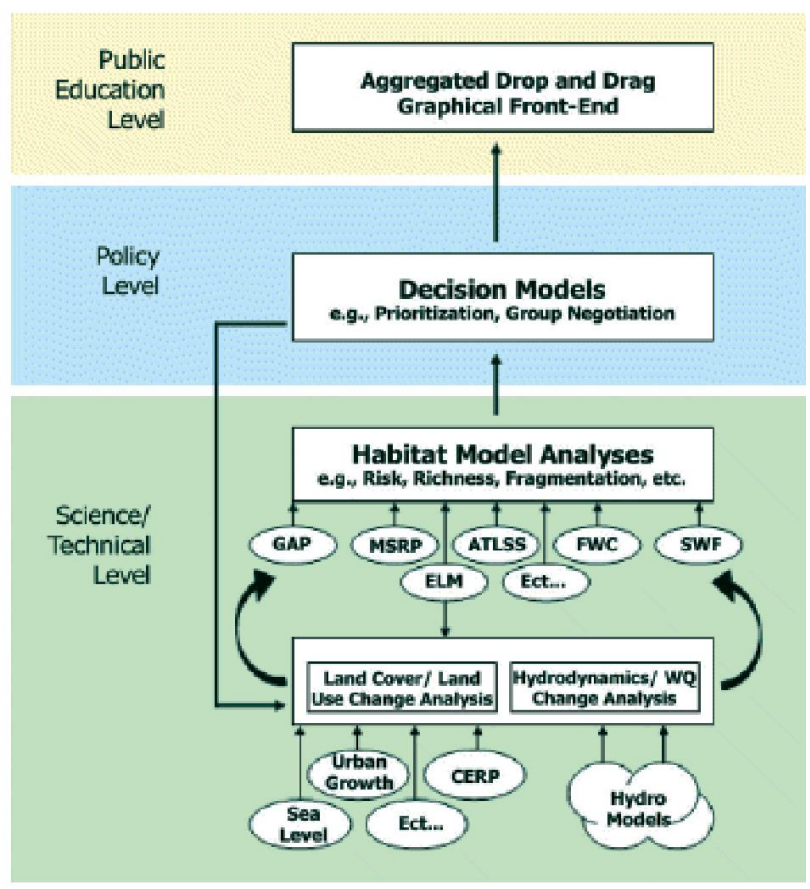

Figure 2. A hierarchical and modular approach to development of a Spatial Decision Support System. Abbreviations represent current habitat models in southern and southwestern Florida. 


\section{Ecological Issues in Southwestern Florida}

The Caloosahatchee and Big Cypress watersheds that make up the SWFFS include mangrove- and seagrass-dominated coastal estuaries. The benthic-based primary productivity of these protected nursery grounds supports fish and microin-vertebrate communities that, in turn, feed many commercial and recreational marine species. Together with these coastal communities, inland short hydroperiod freshwater marshes, wet prairies, and wetland forests are habitat for up to 20 Federally listed species and 43 species of migratory nongame birds of management concern (U.S. Department of the Interior, 2004). Southwestern Florida is also one of the most important regions that support wide-ranging species such as the Florida panther, Florida black bear, and wood stork (Cox and others 1994). Because southwestern Florida is one of the most rapidly developing areas across the Nation, concern has arisen among the public and decision makers about urban and agricultural growth in proximity to extensive public land holdings and privately owned natural areas with the ecological attributes just described.

\section{Southwestern Florida Ecological Evaluations}

The following discussion provides examples of the types of tools and procedures being developed for southwestern Florida evaluations. The SWFFS is an ongoing project, and tools may change substantially over the course of the study.

Ecological evaluations examine the effects of hydrologic change in two geographic regions. In coastal areas, instream changes in water-delivery schedules along the Caloosahatchee River are evaluated for their effect on the Caloosahatchee River estuary. In inland areas, changes in overland hydrologic characteristics are evaluated for their effect on forested and emergent wetlands.

Criteria for assessing ecological effects to southwestern Florida are being developed at three principal scales. The criteria address changes in: (1) potential habitat distributions and quality for individual species, (2) community composition and hydrologic characteristics, and (3) landscape connectivity.

\section{Species Evaluations}

Coastal species evaluation tools include species habitat suitability models for sea trout, American oyster, blue crab, two species of sea grasses (Halodule and Thalassia), and a submerged freshwater grass (Vallisneria). Inland evaluation models are now being created or adapted from existing models for indicators of inland wetland health including:

- Wading birds (wood stork and white ibis)

- Amphibians (change in composition of frog communities)

- Aquatic fauna (changes in composition of forage fish and cray fish communities)

- Measures of regional habitat fragmentation

- Measures of regional habitat connectivity for wide ranging mammals

- Measures of hydrological gradients

Figure 3 shows output from a species habitat model for spotted sea trout in San Carlos Bay and Pine Island Sound at the mouth of the Caloosahatchee River. Maps of potential habitat for sea trout are shown for two alternative water-release schedules along the Caloosahatchee River. The spatially-explicit interface helps staff and decision-makers understand how habitat scores are derived and the distribution of preferred habitats across the study area. In addition to mapping habitat scores, the individual component scores, such as salinity and flow, are mapped so users can quickly assess their contribution to the overall score. The top viewer shows the monthly view. Each scenario is displayed as a group of spatial viewers that map the distribution of Habitat Suitability Index (HSI) values for that species in that month and the distribution of values for each component that leads to the HSI scores. Text boxes within the viewers show values at locations selected by users by clicking on the map. The bottom viewer is the same interface when yearly 
totals are displayed. In this case, when users select a location by clicking on it, the HSI value and all the component values that make up that HSI at that location are graphed for each month of that year.

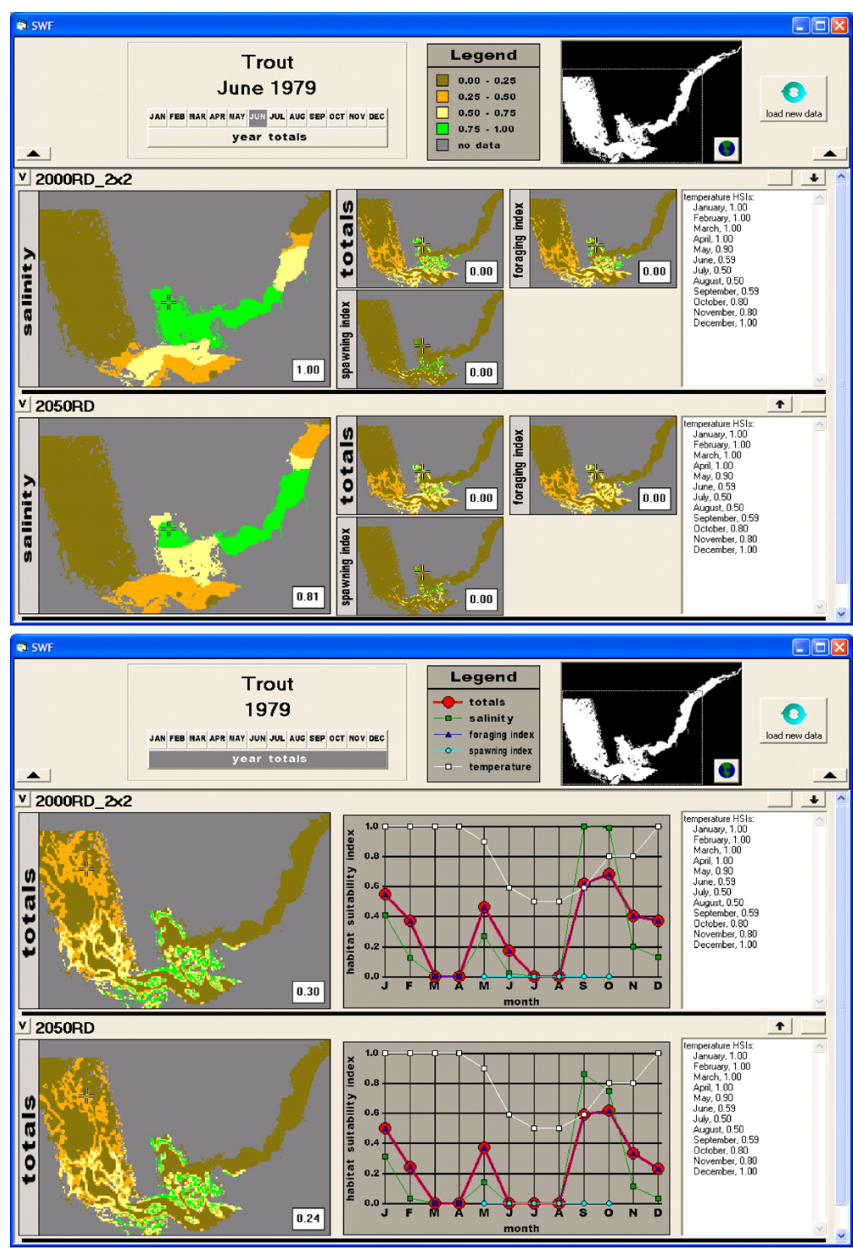

Figure 3. The Southwest Florida Feasibility Model interface showing spotted sea trout habitat suitability.

\section{Community Evaluations}

Community evaluations involve the use of hydrologic models to evaluate hydrologic characteristics within indicator regions in the study area. Indicator regions are representative areas of a single community such as hydric pine flatwoods or cypress prairie. Predevelopment hydrologic characteristics modeled at an indicator region are compared to the same characteristics in alternative hydrologic scenarios using a similarity measure. Alternatives that more closely preserve predevelopment hydrology of a community are ranked as better for maintaining natural conditions at the site.
Community evaluations also include measures of listed-species diversity, overall biological diversity, community fragmentation, and the influence of other landscape features such as proximity to conservation lands or development. A model interface allows managers to spatially assess and map these community measures.

\section{Landscape Evaluations}

Landscape connectivity is a measure of how landscape elements, such as habitat patches, edges and contiguity, affect organism movement and usage of landscape resources (Tischendorf and Fahrig, 2000). The Florida black bear is being used as an umbrella species whose requirements for connectivity across the landscape also protects the habitat and movement requirements of other wide-ranging species (e.g., Florida panther, bobcat). Maintaining connectivity requires large contiguous areas of prefered habitat that are connected by traversable land covers. The large core areas of prefered habitat must be within the dispersal distance of the black bear.

Other measurements of the landscape including habitat patch sizes, road density, the amount of habitat edge, the distribution of short to long hydroperiod wetlands, and the distribution of distances from wetlands to uplands, all contribute to characterizing the regional quality of habitat.

These measures are used to weigh the effects of alternative hydrologic and land use scenarios against a predevelopment scenario.

\section{Decision Models}

Ecological models provide essential output for evaluating landscape habitat changes, but do not provide it in a form that: (1) permits collective evaluations of the habitat changes, or (2) allows decisions to be made from multiple evaluations. Decision analysis provides tools for systematically formulating and evaluating multiple criteria and explaining why (under several conflicting preferences) a particular decision was made (Lahdelma and others, 2000). 
Figure 4 presents a procedural relation between scientific/ technical evaluations and policy making in an adaptive management framework. Conceptual models are an effective initial tool for group identification of sources of stressors and linkages to attributes in the environment. Criteria, or performance measures, are selected as measurable values of identified attributes and are used to evaluate success of implemented plans. For example, if an attribute of the natural environment is oyster community structure and function, then criteria for that attribute may be oyster growth, disease, mortality, and recruitment. Scientists place expected values on these criteria under alternative scenarios of environmental change. This task is usually accomplished with ecological modeling. Decision makers then determine the importance of each of these criteria and use this information to evaluate different alternatives. Decision models aid in weighing and evaluating alternatives and may also help decision makers pinpoint conflicts between objectives and conceptualize new alternatives that minimize these conflicts (Ozernoy, 1984). Once an alternative is selected and implemented, expected environmental change is compared to actual conditions through monitoring and directed experimentation, which may lead again to reevaluations of criteria and implemented plans.

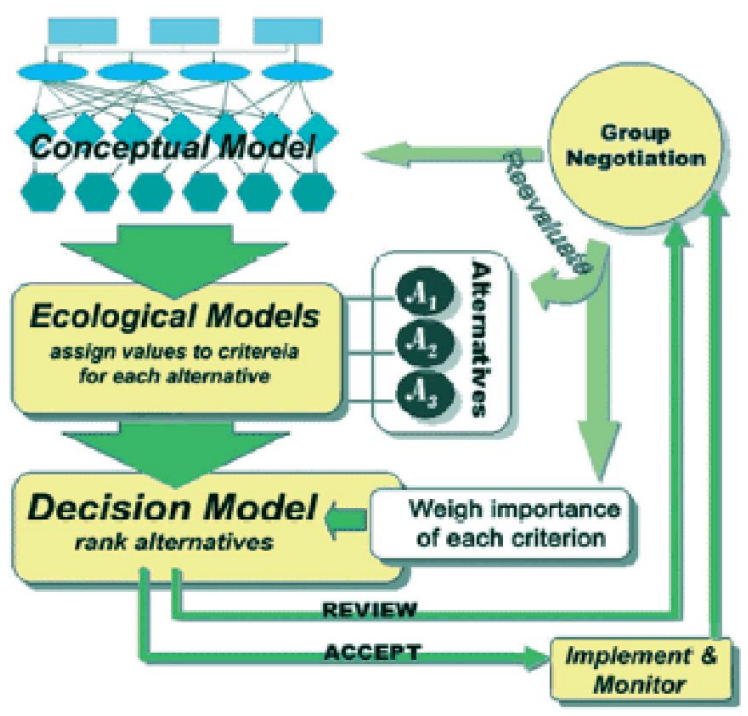

Figure 4. The decision support process.

Multicriteria decision analysis calls for agencies to define issues, propose alternative solutions, and develop measurable criteria for evaluating the performance of each alternative. Decision tools and graphical methods help provide a critical and careful examination of the process. In southern and southwestern Florida, the need for evaluation approaches that help to structure the decision process is increasingly felt by natural resource personnel as indicated by results from a preliminary decision support survey (Pearlstine and others, 2003).

\section{References}

Cox, J., Kautz, R., MacLaughlin, M., and Gilbert, T., 1994, Closing the gaps in Florida's wildlife habitat conservation system. Tallahassee, Florida, Office of Environmental Services, Florida Fish and Wildlife Conservation Commission.

Kingston, R., Carver, S., Evans, A., and Turton, I, 2000, Web-based public participation geographical information systems: An aid to local environmental decision-making. Computers, Environment and Urban Systems v. 24, p. 109-125.

Lahdelma, R., Salminen, P., and Hokkanen, J., 2000, Using multicriteria methods in environmental planning and management. Environmental Management, v. 26, p. 595-605.

Ozernoy, V., 1984, Generating alternatives in multiple criteria decision making problems: A survey. In Y. Haimes, and V. Chankong (eds.), Decision Making with Multiple Objectives. New York, Springer-Verlag.

Pearlstine, L.G., and Mazzotti, F.J., 2003, A spatially-explicit decision support system for Everglades risk assessment and restoration: An annual report to the U.S. Geological Survey Florida Integrated Science Center. Fort Lauderdale, Florida, Fort Lauderdale Research and Education Center, University of Florida.

Rauscher, H.M. 1999, Ecosystem management decision support for Federal forests in the United States: A review. Forest Ecology and Management, v. 114, p. 173-197. 
Tischendorf, L., and Fahrig, L., 2000, On the usage and measurement of landscape connectivity. Oikos, v. 90, p 7-19.

U.S. Department of the Interior, 2004, Science plan in support of ecosystem restoration, preservation, and protection in South Florida. Accessed on August 26, 2004 at http://sofia.usgs.gov/publications/reports/doi-scienceplan/ 